\title{
Folate deprivation promotes mitochondrial oxidative decay: DNA large deletions, cytochrome $c$ oxidase dysfunction, membrane depolarization and superoxide overproduction in rat liver
}

\author{
Chun-Min Chang, Chu-Ching Yu, Hsin-Te Lu, Yi-Fang Chou and Rwei-Fen S. Huang* \\ Department of Nutritional Science, Fu-Jen University, Hsin-Chuang, Taiwan, ROC
}

(Received 13 July 2006 - Revised 25 October 2006 - Accepted 10 November 2006)

\begin{abstract}
Little is known about the biological effect of folate in the protection against mitochondrial (mt) oxidative decay. The objective of the present study was to examine the consequence of folate deprivation on $\mathrm{mt}$ oxidative degeneration, and the mechanistic link underlying the relationship. Male Wistar rats were fed with an amino acid-defined diet containing either 8 (control) or 0 (folate-deficient, FD) mg folic acid/kg diet. After a 4-week FD feeding period, significant elevation in oxidative stress was observed inside the liver mitochondria with a $77 \%$ decrease in mt folate level $(P<0.001)$, a $28 \%$ reduction in glutathione peroxidase activity $(P=0.0333)$, a $1 \cdot 2$-fold increase of mt protein carbonyls $(P=0.0278)$ and an accumulated $4834 \mathrm{bp}$ large-scale deletion in mtDNA. The elicited oxidative injuries in FD liver mitochondria were associated with $30 \%$ reduction of cytochrome $c$ oxidase $(\mathrm{CcOX})$ activity $(P=0.0264)$. The defective $\mathrm{CcOX}$ activity in FD hepatocytes coincided with mt membrane potential dissipation and intracellular superoxide elevation. Exposure of FD hepatocytes to pro-oxidant challenge ( $32 \mu \mathrm{M}$-copper sulphate for $48 \mathrm{~h}) \mathrm{led}$ to a further loss in $\mathrm{CcOX}$ activity and mt membrane potential with a simultaneous increase in superoxide production. Preincubation of pro-oxidanttreated FD hepatocytes with supplemental folic acid $(10-1000 \mu \mathrm{M})$ reversed the mt oxidative defects described earlier and diminished superoxide overproduction. Increased supplemented levels of folic acid strongly correlated with decreased lipid peroxidation $(\gamma-0 \cdot 824, P=0 \cdot 0001)$ and protein oxidative injuries $(\gamma-0.865, P=0.0001)$ in pro-oxidant-challenged FD liver mitochondria. Taken together, the results demonstrated that folate deprivation induces oxidative stress in liver mitochondria, which is associated with CcOX dysfunction, membrane depolarization and superoxide overproduction. The antioxidant activity of supplemental folic acid may partially, if not fully, contribute to the amelioration of pro-oxidantelicited mt oxidative decay.
\end{abstract}

Folate deprivation: Liver mitochondrial decay: $\mathrm{CcOX}$ activity: Membrane depolarization: Oxidative stress

The biochemical function of folate involved in one-carbon metabolism critical for cellular proliferation and nuclear DNA repair has been well documented (Shane, 1995). In the last decade, growing literature evidence suggests another potential role of folate on antioxidant action (Nakano et al. 2001; Mayer et al. 2002; Rezk et al. 2003; Coppola et al. 2005). Numerous investigations have shown that folate deprivation elevated pro-oxidant homocysteine levels (Huang et al. 2001), impaired antioxidant enzymatic activities (Chen et al. 2001; Huang et al. 2001), increased reactive oxygen species (ROS) generation and lipid peroxidation (Chern et al. 2001). However, the basis for folate status and oxidative insults is unclear. Folic acid has been proposed to scavenge peroxyl radicals, azide radicals and hydroxyl radicals in an in vitro radical reaction model system (Joshi et al. 2001). Particularly, the intracellular superoxide-scavenging capability of folic acid was observed in various pro-oxidant-challenged cells such as homocysteine thiolactone-treated HL60 cells (Huang et al. 2002) and 7-ketocholesterol-treated U937 cells (Huang et al. 2004). Increased folate intake was found to improve endothelial function in patients with coronary artery disease, which is largely independent of homocysteine lowering action. Instead, reduction of intracellular endothelial superoxide may have contributed to the effect of folate (Doshi et al. 2001). The studies mentioned earlier raise the potential question about the corresponding mechanism responsible for folate's superoxide-scavenging capability.

The mitochondrial $(\mathrm{mt})$ electron transport chain has been recognized as a major intracellular source of superoxide anion generation (Ksenzenko et al. 1983; Turrens et al. 1985). When superoxide production exceeds the capacity of detoxification and repair pathways, oxidative damage to $\mathrm{mt}$ protein, DNA and phospholipid occurs, which may further disrupt electron transport chain and constitute a ROS-generated vicious cycle leading to apoptotic signalling and cellular death (Cadenas \& Davies, 2000; Ravagnan et al. 2002). The increased oxidative stress is also critical in the accumulation of the most abundant mtDNA mutations, a large-scale deletion of $4977 \mathrm{bp}$ in ageing human tissues (Cortopassi et al. 1992) and 4834 bp large deletion in mtDNA (mtDNA ${ }^{4834}$ deletion)

Abbreviations: CcOX, cytochrome $c$ oxidase; FD, folate-deficient; mt, mitochondrial; mtDNA ${ }^{4834}$ deletion, 4834 bp large deletion in mtDNA; ROS, reactive oxygen species.

* Corresponding author: Dr Rwei-Fen S. Huang, fax +886229021215, email rweifen@mails.fju.edu.tw 
in ageing rodent tissues (Edris et al. 1994). This mtDNA large deletion removes $30 \%$ of mtDNA molecules which comprise a part of the electron chain transport. Accumulation of this mutant mtDNA was associated with mt functional decline, elevated ROS generation and increased oxidative damage at the cellular levels (Cortopassi \& Wang, 1995; Lu et al. 1999).

Conditions of insufficient folate have been reported to cause disruption of $\mathrm{mt}$ homeostasis. Mt degeneration was found in the cerebrocortical microvascular wall of the brain of folatedeprived rats (Kim et al. 2002). Ho et al. (2003) noticed an increase of depolarized mitochondria in cortical neuron resulting from folate deprivation. Folate may protect against the accumulation of the mtDNA ${ }^{4834}$ deletion in liver of chemotherapeutic drug-treated rats (Branda et al. 2002) and ageing rats (Crott et al. 2005). However, it is currently not known whether $\mathrm{mt}$ abnormalities elicited by folate deficiency are associated with increased oxidative stress and if folate could act as an antioxidant to protect against oxidative stress-related mt decay as well as superoxide overproduction. The objective of the present study was to investigate the link underlying these relationships. Using the in vivo animal model, oxidative markers of mt decay including antioxidant defences, lipid and protein oxidative damage, $\mathrm{mtDNA}^{4834}$ deletion and respiratory electron chain activity were assessed in the liver of rats fed with folate-deficient (FD) or folate-replete (control) diets. An ex vivo model of primary hepatocytes isolated from FD and control rats was established to study mt dysfunction and superoxide overproduction in folic acid-supplemented and pro-oxidant-challenged conditions.

\section{Materials and methods}

\section{Animals and experimental diets}

A specially formulated L-amino acid-defined FD diet with $1 \%$ succinylsulphothiazole was specially formulated by Harlan Teklad (Madison, WI, USA). The basal FD diet supplemented with $8 \mathrm{mg}$ folic acid/kg was designated as the control diet (Walzem \& Clifford, 1988; Huang et al. 2001). The experimental protocols were approved by the Institutional Animal Care Committee of Fu-Jen University. Male weanling Wistar rats ( $n$ 60) were randomly assigned to the FD or control diet using a pair-fed model as previously described by Huang et al. (2001). Twelve animals ( $n 6$ for the FD and control group) were used for each of the following measured parameters: antioxidant assay, DNA deletion assay, cytochrome $c$ oxidase $(\mathrm{CcOX})$ staining assay, ROS and $\mathrm{mt}$ membrane potential assay. After a 4 -week period, the rats were killed to collect tissues, or primary hepatocytes were isolated for further analysis.

\section{Primary hepatocyte isolation}

Primary hepatocytes were isolated by using a two-stage collagenase perfusion technique according to Lii \& Hendrich (1993). Primary hepatocytes were cultured in collagencoated plates and maintained in FD RPMI-1640 medium supplemented with $10 \%$ heat-inactivated fetal bovine serum, antibiotics (2000 U/l penicillin, $20 \mathrm{mg} / \mathrm{l}$ streptomycin, $100 \mathrm{mg} / \mathrm{l}$ fungizone), $5 \mathrm{mg} / \mathrm{l}$ transferrin, $5 \mathrm{mg} / \mathrm{ml}$ insulin and various levels of folic acid. The normal culture medium contained $1.5(\mathrm{SD} 0.4) \mu \mathrm{M}$-folate as determined by the Lactobacillus casei method (Horne \& Patterson, 1988). The cell culture was incubated in a $\mathrm{CO}_{2}$ incubator at $37^{\circ} \mathrm{C}$.

\section{Preparation of folic acid stock solution}

A stock solution $(10 \mathrm{mmol} / \mathrm{l})$ of folic acid (pteroylmonoglutamic acid) was prepared by dissolving $44 \mathrm{mg}$ folic acid in $10 \mathrm{ml}$ $\mathrm{NaHCO}_{3}(10 \mathrm{~g} / \mathrm{l})$ solution. To make up media with various levels of folate, folate stock was added to FD medium and the $\mathrm{pH}$ was adjusted to 7.4. The stock solution was freshly prepared before performing each experiment.

\section{Preparation of mitochondrial fraction}

Rat liver mitochondria were isolated by conventional differential centrifugation in a STE buffer containing $250 \mathrm{mmol} / 1$ sucrose, $5 \mathrm{mmol} / \mathrm{l}$ Tris-HCl $(\mathrm{pH} 7 \cdot 4)$ and $1 \mathrm{mmol} / \mathrm{l}$ EGTA (Johnson \& Lardy, 1967). Briefly, liver homogenates were prepared with the STE buffer by using a Potter-Elvehjemtype homogenizer. The homogenate was centrifuged twice at $1000 \mathrm{~g}$ at $4{ }^{\circ} \mathrm{C}$ and the mitochondria were then pelleted by centrifugation at $10000 \mathrm{~g}$ for $30 \mathrm{~min}$. The purity was determined by measuring the relative specific activities of glutamate dehydrogenase and lactate dehydrogenase in the supernatant and the mt pellet (Evans, 1992). Yields of mt fractions, as reflected by their protein content (Bradford, 1976), were similar in various experimental groups.

\section{Analysis of mitochondrial antioxidant status and oxidative insults}

Folate levels were assessed using a microbiological assay performed by cryoprotected Lactobacillus casei in ninetysix-well microtitre plates (Horne \& Patterson, 1988). The levels of $\mathrm{mt}$ reduced glutathione (Hissin \& Hilf, 1976), Mn-superoxide dismutase (Marklund \& Marklund, 1974) and glutathione peroxidase (Tappel, 1977) were determined according to the methods as previously described. Lipid peroxidation was quantified by measuring the production of thiobarbituric acid-reactive substances (Fraga et al. 1988). Protein carbonyl contents in mitochondria were evaluated as described by Reznick \& Packer (1994).

\section{Analysis of the mitochondrial DNA 4834 deletion}

Total rat liver DNA was extracted (Huang et al. 2004), and the specific primers for the $\mathrm{mtDNA}^{4834}$ deletion were adapted from the report of Branda et al. (2002). The thermal profile for amplification of the $\mathrm{mtDNA}^{4834}$ deletion was initiated with a $10 \mathrm{~min}$ denaturation period at $95^{\circ} \mathrm{C}$, followed by forty cycles of $95^{\circ} \mathrm{C}$ for $15 \mathrm{~s}, 60^{\circ} \mathrm{C}$ for $60 \mathrm{~s}$ and $72^{\circ} \mathrm{C}$ for $60 \mathrm{~s}$. The profile was completed within a $10 \mathrm{~min}$ period at $72{ }^{\circ} \mathrm{C}$. All reactions were carried out in a GeneAmp DNA thermal cycler (Perkin Elmer, Wellesley, MA, USA). The amplified DNA fragments were separated by electrophoresis on a $2 \%$ agarose gel at $100 \mathrm{~V}$ for $40 \mathrm{~min}$. 
Semi-quantification of deleted mitochondrial DNA heteroplasmy

To confirm and further analyse the heteroplasmy of the mtDNA deletion, we designed primers targeting a mtDNA region within the NDl gene that is rarely deleted (forward primers: $5^{\prime}$-GTCTCAGGCTTTAACGTCG-3' ; reverse primer: $5^{\prime}$-GGTCATATCGAAAACGGGG-3'), and a region of the CcOX subunit III gene that is deleted in the 4834 bp deletion (forward primer: $5^{\prime}$-TTCCAGCCTAGTTCCTACC- $3^{\prime}$; reverse primer: $5^{\prime}$-GTGTCAGTATCATGCTGCG-3'), producing amplicons of 229 and $418 \mathrm{bp}$, respectively. Amplification of the $\mathrm{ND} 1$ and $\mathrm{CCOXIII}$ primers was initiated with a $60 \mathrm{~s}$ denaturation period at $94^{\circ} \mathrm{C}$, followed by thirty-two cycles of $95^{\circ} \mathrm{C}$ for $60 \mathrm{~s}, 54^{\circ} \mathrm{C}$ for $60 \mathrm{~s}$ and $72{ }^{\circ} \mathrm{C}$ for $60 \mathrm{~s}$. This profile was completed within a $10 \mathrm{~min}$ period at $72{ }^{\circ} \mathrm{C}$. To semi-quantify the relative amount of mtDNA ${ }^{4834} \mathrm{del}-$ etion, total DNA extracted from each of the liver samples was serially diluted between $2^{0}$ - and $2^{23}$-fold with distilled water. The proportion of deleted $C c O X I I I$ to wild-type mtDNA, i.e. the deleted mtDNA heteroplasmy, was determined by the percentage of the highest dilution that caused the PCR product amplified from COXIII to be visible on the gel to that which caused the PCR product from total mtDNA (ND1) to be visible under identical conditions (Lee et al. 1994).

\section{Analysis of respiratory complexes activity}

According to the methods of Trounce et al. (1996), the activity of oxidative phosphorylation enzyme complexes was assayed by using mt protein extracted from rat livers. NADH-cytochrome $c$ oxidoreductase was measured by the complex I + III coupled assay with NADH-dependent reduction of cytochrome $c$ at 550 minus $540 \mathrm{~nm}$ (extinction coefficient: $19 \cdot 0 \mathrm{~mm}^{-1} \mathrm{~cm}^{-1}$ ). Succinate-cytochrome $c$ oxidoreductase was assayed via the reduction of cytochrome $c$ by complex III coupled to succinate oxidation through complex II at 550 minus $540 \mathrm{~nm}$. CcOX activity (complex IV) was measured by following the oxidation of reduced cytochrome $c$ at $550 \mathrm{~nm}$ by using an extinction coefficient of $\varepsilon_{550}=27.7 \mathrm{mM}^{-1} \mathrm{~cm}^{-1}$. Cytochrome $c$ was reduced by L-ascorbate, purified by using a Sephadex G-25 column (Pharmacia Biotech, Piscataway, NJ, USA) and checked for full reduction by measuring absorbance at 550 and $565 \mathrm{~nm}$. Histochemical reaction of $\mathrm{CcOX}$ was performed according to the method described by Seligman et al. (1968) in which
CcOX activity was assessed by $3,3^{\prime}$-diaminobenzidein staining after reducing cytochrome $c$.

\section{Analysis of mitochondrial membrane potential and reactive oxygen species production}

Mt membrane potential was quantified by rhodamine 123 staining and flow cytometric analysis as described in detail elsewhere (Huang et al. 2004). Intracellular ROS were assayed using the fluorescent dyes of dihydroethidine for superoxide anion and $2^{\prime}, 7^{\prime}$-dichlorofluorescein diacetate for other general ROS (Huang et al. 2004), and analysed using a flow cytometer (Coulter Corporation, Miami, FL, USA).

\section{Statistical analyses}

Data are presented as means and standard deviations. Effects of dietary folate intake on hepatic mtDNA mutation, function and oxidative injury were analysed by Student's $t$ test or by one-way ANOVA with Duncan's multiple range tests using the General Linear Model of SAS (SAS Institute Inc., Cary, NC, USA). Differences were considered significant at $P<0 \cdot 05$. The Pearson correlation coefficients were used to measure the association among supplemental folate levels, mt lipid and protein oxidative injury variables under pro-oxidant-treated conditions.

\section{Results}

Mitochondrial antioxidant status and oxidative injuries in rat liver during folate deprivation

After a 4-week dietary folate deprivation, plasma folate levels of FD rats were significantly lower than those of control rats (72 (SD 23) v. 113 (SD 7) ng/ml; $P<0.05$ ), confirming the depleted folate status in FD rats. Table 1 shows the changes in the $\mathrm{mt}$ antioxidant defence system and oxidative injuries during folate deficiency. Compared with the controls, the $\mathrm{Mn}$-superoxide dismutase activity and the reduced glutathione levels remained relatively unchanged, and the mt glutathione peroxidase activity significantly decreased in rat liver after a 4 -week FD feeding period $(P=0.0333)$. In particular, 4-week folate deprivation remarkably decreased $\mathrm{mt}$ folate levels by $77 \%$ as compared to the control values $(P<0 \cdot 001)$. The $\mathrm{mt}$ thiobarbituric acid-reactive substances

Table 1. Effects of folate deprivation on mitochondrial $(\mathrm{mt})$ antioxidant status and oxidative injuries in rat liver $(n 6) \dagger$ (Mean values and standard deviations)

\begin{tabular}{|c|c|c|c|c|c|c|c|c|c|c|c|c|}
\hline \multirow[b]{3}{*}{ Diet } & \multicolumn{8}{|c|}{ Mitochondrial antioxidant status } & \multicolumn{4}{|c|}{ Mitochondrial oxidative insults } \\
\hline & \multicolumn{2}{|c|}{$\begin{array}{l}\mathrm{Mn}-\mathrm{SOD} \\
\text { (units/mg mt } \\
\text { protein) }\end{array}$} & \multicolumn{2}{|c|}{$\begin{array}{l}\text { GPX (units/mg } \\
\text { mt protein) }\end{array}$} & \multicolumn{2}{|c|}{$\begin{array}{l}\mathrm{GSH}(\mathrm{nmol} / \mathrm{mg} \\
\mathrm{mt} \text { protein) }\end{array}$} & \multicolumn{2}{|c|}{$\begin{array}{l}\text { Folate }(\mathrm{pg} / \mathrm{mg} \\
\mathrm{mt} \text { protein) }\end{array}$} & \multicolumn{2}{|c|}{$\begin{array}{l}\text { TBARS } \ddagger \text { (nmol/ } \\
\text { mg mt protein) }\end{array}$} & \multicolumn{2}{|c|}{$\begin{array}{l}\text { Protein carbonyls } \\
\text { (nmol/mg mt } \\
\text { protein) }\end{array}$} \\
\hline & Mean & SD & Mean & SD & Mean & SD & Mean & SD & Mean & SD & Mean & SD \\
\hline Control & $7 \cdot 6$ & 1.9 & 125 & 40 & 34.5 & $2 \cdot 3$ & 69 & 1.0 & 1.01 & 0.24 & 1.90 & 0.03 \\
\hline FD & 8.2 & 1.5 & $90^{*}$ & 10 & $33 \cdot 1$ & 1.3 & $16^{\star}$ & 1.0 & 1.01 & 0.24 & $2 \cdot 18^{*}$ & 0.24 \\
\hline
\end{tabular}

FD, folate-deficient; GPX, Se-glutathione peroxidase; GSH, reduced glutathione; $\mathrm{Mn}-\mathrm{SOD}, \mathrm{Mn}-$ superoxide dismutase; TBARS, thiobarbituric acid-reactive substances. Mean values were significantly different from those of the control group: ${ }^{\star} P<0.05$.

† Wistar rats were fed with the FD or control diet for 4 weeks and liver mitochondria were isolated. For details of procedures, see Materials and Methods.

$\ddagger$ Measured as malondialdehyde equivalents. 
production was not different between FD and control livers. In contrast, folate deprivation significantly increased the $\mathrm{mt}$ contents of protein carbonyls in rat liver $(P=0.0278)$.

\section{Detection of mitochondrial DNA ${ }^{4834}$ deletion and heteroplasmy in folate-deficient rat liver}

As shown in the representative agarose image in Fig. 1(A), the mtDNA $^{4834}$ deletion was detected as an $81 \mathrm{bp}$ PCR product in the FD (lanes 4-6) but not in the controls (lanes 1-3). In Fig. 1(B), there was a decrease in the intensity of $418 \mathrm{bp}$ PCR product (deleted mtDNA: $\mathrm{CcOXIII)}$ in FD rat livers compared with the controls, while $229 \mathrm{bp}$ PCR product (wild-type mtDNA: ND1) was amplified similarly in both the groups. By normalizing with ND1 intensity, the relative ratio of $\mathrm{CcOXIII}$ to $N D 1$ was 1.11 (SD 0.12) for the controls and 0.84 (SD 0.09) for the FD group (six rats in each group; $P=0.0312$ ). The data confirmed the deletion of mtDNA in FD rat liver to result in CcOXIII gene loss. Using a serial dilution PCR method, the highest dilution that caused the PCR product amplified from $\mathrm{CcOXIII}$ to be visible on the gel was $2^{8}$ (Fig. $1(\mathrm{C})$ ) and $2^{11}$ for $N D 1$ (data not shown) in FD rat liver. The deleted mtDNA heteroplamy was calculated as the ratio of dilution-fold in $C C O X I I I / N D 1$ from six FD rats, i.e. 0·104 (SD 0.035) \%.

\section{Respiratory chain activity in mitochondria of control and folate-deficient rat liver}

In order to determine if increased oxidative insults in mitochondria of FD rat liver were associated with mt dysfunction on the respiratory chain, the activities of the complex I-IV were measured. Table 2 demonstrates that only trace glutamate dehydrogenase specific activity ( $\mathrm{mt}$ matrix maker enzyme) was detectable in cytosol, indicating that mitochondria are intact during the isolation procedure. Activities of $\mathrm{NADH}$-cytochrome $c$ oxidoreductase (complex I + III) and succinate-cytochrome $c$ oxidoreductase (complex II + III) did not differ between control and FD rat mitochondria. $\mathrm{CcOX}$ (respiratory complex IV) activity in FD liver mitochondria was significantly reduced by $30 \%$ when compared to that in the controls $(P=0.0264)$.

\section{Supplemental folic acid modulated cytochrome c oxidase activity in the absence/presence of pro-oxidant challenge}

The decreased $\mathrm{CcOX}$ activity in FD rat liver was confirmed by histochemical analysis on primary hepatocytes isolated from FD and control rats (Fig. 2(A, B)). The circled hepatocytes represent the cells with reduced $\mathrm{CcOX}$ activity. Additional pro-oxidant challenge ( $32 \mu \mathrm{mol} / 1 \mathrm{CuSO}_{4}$ treatment for $48 \mathrm{~h}$ ) further decreased $\mathrm{CcOX}$ activity in both FD and control hepatocytes (Fig. 2(C, D)). Preincubation of FD and control hepatocytes with 100 and $1000 \mu \mathrm{mol} / \mathrm{l}$ folic acid for $4 \mathrm{~h}$ before oxidant treatment restored CcOX activity (Fig. 2(E-H)).

Supplemental folic acid modulated mitochondrial membrane potential in the absence/presence of exogenous pro-oxidant challenge

To investigate if the altered activity of $\mathrm{CcOX}$ in FD hepatocytes was associated with membrane dysfunction, mt

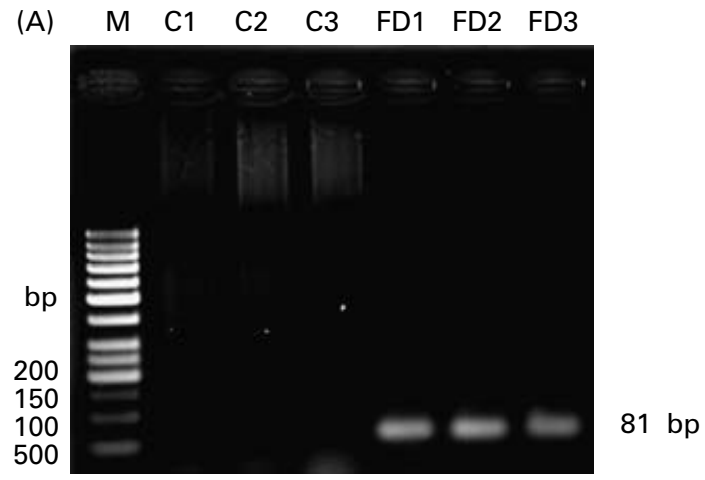

$\begin{array}{llllllll}\text { (B) } & M & \mathrm{C} 1 & \mathrm{C} 2 & \mathrm{C} 3 & \mathrm{FD} 1 & \mathrm{FD} 2 & \text { FD3 }\end{array}$

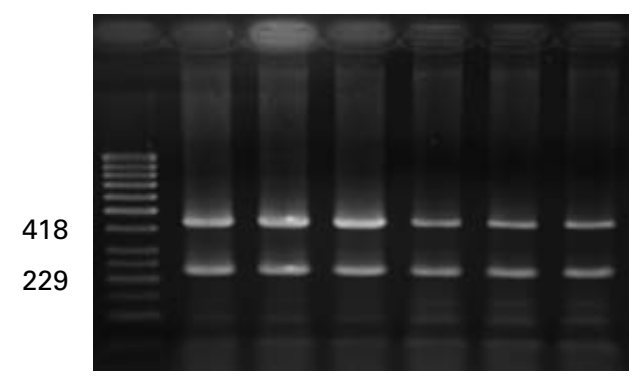

(C) $\quad 2^{3} \quad 2^{4} \quad 2^{5} \quad 2^{6} \quad 2^{7} \quad 2^{8} \quad 2^{9} \quad \begin{aligned} & M\end{aligned}$

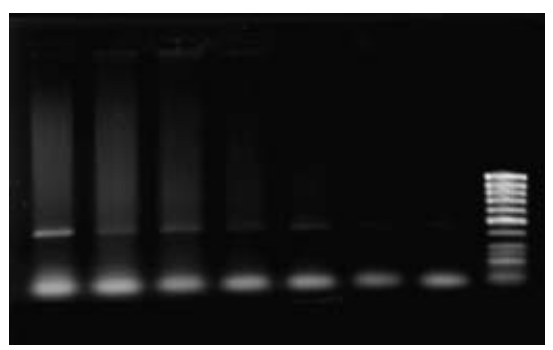

Fig. 1. Analysis of the $4834 \mathrm{bp}$ large deletion in mitochondrial DNA ( $m \mathrm{mLNA}^{4834}$ deletion) in rat liver. (A), The representative agarose image for the $\mathrm{mtDNA}^{4834}$ deletion in livers of three rats fed with the control (C) or folate-deficient (FD) diet for 4 weeks. Total DNA was extracted and the $\mathrm{mtDNA}^{4834}$ deletion was detected using the PCR technique described in the Materials and Methods. PCR amplification of the $4834 \mathrm{bp}$ deleted mtDNA sequence resulted in an $81 \mathrm{bp}$ product. (B), Representative autoradiogram of the heteroplasmy of the mtDNA deletion in the liver of one rat fed with the control (C) or FD diet for 4 weeks. The gel image distinguishes between mtDNA outside the deletion region $(229 \mathrm{bp})$ and the CcOXIII gene within the deletion region ( $418 \mathrm{bp}$ ) on the basis of size. Lane $\mathrm{M}$ contains a molecular weight marker. Each lane refers to a sample from a FD and a pair-fed control rat liver. (C), Representative autoradiogram showing the proportion of the CCOXIII gene relative to the ND1 gene in FD rat liver after serial dilution PCR analysis. Total DNA extracted from each of the liver samples was serially diluted between $2^{0}$ - and $2^{23}$-fold with distilled water.

depolarization was analysed. Fig. 3 shows that FD hepatocytes with defective $\mathrm{CcOX}$ function had a significantly higher percentage of depolarized mitochondria than the controls. Pro-oxidant treatment of FD hepatocytes $\left(32 \mu \mathrm{mol} / 1 \mathrm{CuSO}_{4}\right.$ for $48 \mathrm{~h}$ ) aggravated $\mathrm{mt}$ depolarization, as revealed by a 6-fold increase in depolarized cell fractions compared with the untreated FD hepatocytes. Supplemental folic acid at $100-1000 \mu \mathrm{mol} / 1$ significantly alleviated pro-oxidant-induced mt depolarization. 
Table 2. Effect of folate deprivation on activities of liver mitochondrial respiratory complexes $(n 6) \dagger$ (Mean values and standard deviations)

\begin{tabular}{|c|c|c|c|c|c|c|c|c|c|c|}
\hline \multirow[b]{3}{*}{ Rat liver } & \multicolumn{4}{|c|}{$\begin{array}{l}\text { Glutamate dehydrogenase } \\
(\Delta A / \text { min per mg protein) } \ddagger\end{array}$} & \multicolumn{6}{|c|}{$\begin{array}{c}\text { Mitochondrial enzyme complex } \\
\text { (nmol/min per mg mitochondrial protein) }\end{array}$} \\
\hline & \multicolumn{2}{|c|}{ Cytosol } & \multicolumn{2}{|c|}{ Mitochondria } & \multicolumn{2}{|c|}{$\operatorname{NCCR}(I+I I I)$} & \multicolumn{2}{|c|}{$\operatorname{SCCR}(I I+I I I)$} & \multicolumn{2}{|c|}{ CcOX (IV) } \\
\hline & Mean & SD & Mean & SD & Mean & SD & Mean & SD & Mean & SD \\
\hline Control & 0.79 & 0.03 & $10 \cdot 12$ & 0.12 & $32 \cdot 6$ & $3 \cdot 1$ & 34.5 & 3.5 & 93.5 & $10 \cdot 0$ \\
\hline FD & 0.75 & 0.07 & 9.83 & 0.08 & $30 \cdot 7$ & $2 \cdot 7$ & 31.3 & $2 \cdot 0$ & $64.0^{*}$ & $8 \cdot 7$ \\
\hline
\end{tabular}

CcOX, cytochrome $c$ oxidase; FD, folate-deficient; NCCR, NADH-cytochrome-c oxidoreductase; SCCR, succinate-cytochrome $c$ oxidoreductase.

Mean values were significantly different from those of the control group: ${ }^{*} P<0.05$.

† Wistar rats were fed with the FD or control diet for 4 weeks and liver mitochondria were isolated and enzymatic activities were assayed. For details of procedures, see Materials and Methods.

‡ Specific enzyme activity of glutamate dehydrogenase, a mitochondrial marker enzyme.

(A)

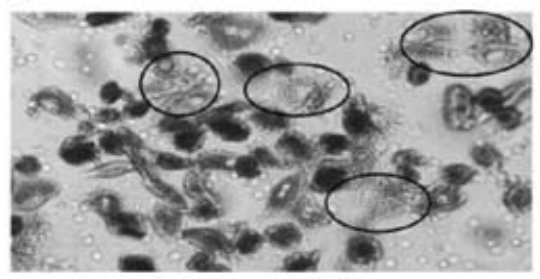

(C)

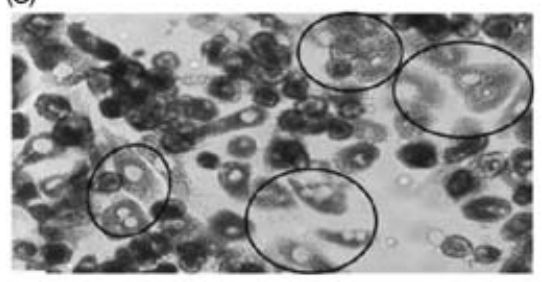

(E)

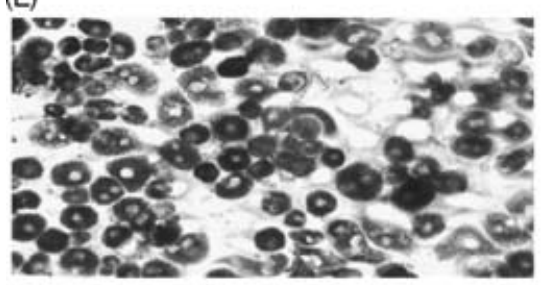

(G)

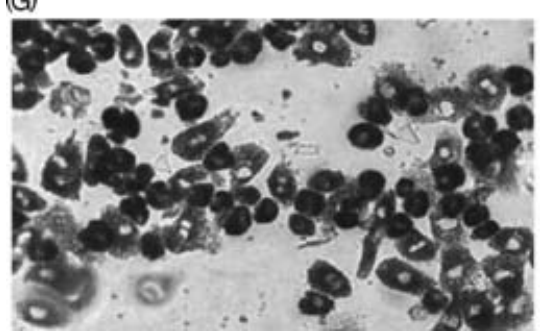

(B)

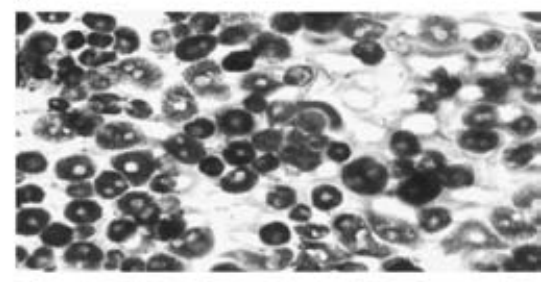

(D)

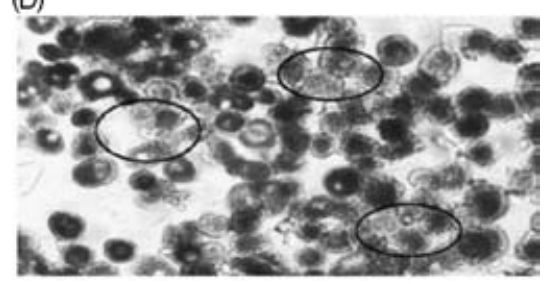

(F)
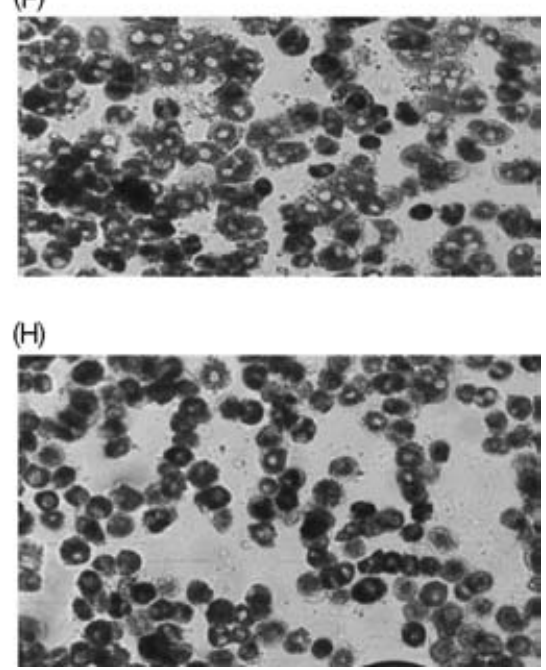

Fig. 2. Supplemental folic acid-modulated cytochrome $c$ oxidase (CcOX) activity in the absence/presence of pro-oxidant challenge. Primary hepatocytes isolated from rats fed folate-deficient (FD; A, C, E, G) or control (B, D, F, H) diets were cultured in FD or complete RPMI medium, respectively. FD and control hepatocytes were preincubated with supplemental folic acid at levels of $0(A-D), 100 \mu \mathrm{M}(E, F)$ and $1000 \mu \mathrm{M}(G, H)$ for $4 \mathrm{~h}$, treated with pro-oxidant (32 $\mu \mathrm{M}$-copper sulphate) for $48 \mathrm{~h}(\mathrm{C}-\mathrm{H})$, and then were harvested for histochemical assay of $\mathrm{CcOX}$ activity as described in the Materials and Methods. Hepatocytes in the circular markers represent the cells with reduced $\mathrm{CcOX}$ activity. 


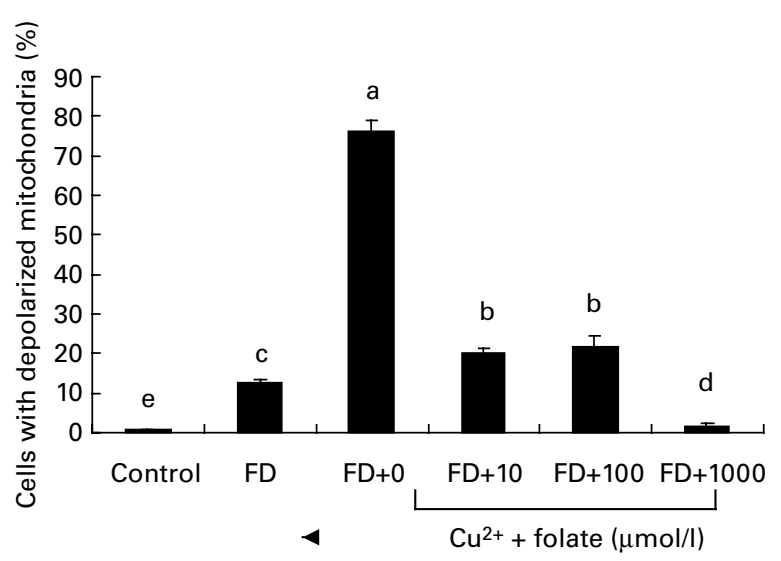

Fig. 3. Supplemental folic acid-modulated mitochondrial membrane potential in the absence/presence of pro-oxidant challenge. Culture conditions and $\mathrm{CuSO}_{4}$ treatment are as described in Fig. 2. The uptake of R123 was analysed by flow cytometry. Values are means with their standard deviations depicted by vertical bars $(n 6)$. ${ }^{a-e}$ Mean values with unlike letters were significantly different $(P<0.05)$. FD, folate-deficient.

Supplemental folic acid reduced superoxide, but not general reactive oxygen species, production in the absence/presence of exogenous pro-oxidant challenge

Both $\mathrm{CcOX}$ inhibition and mt membrane depolarization are known to produce ROS generation. Changes of intracellular ROS in general or superoxide in particular in the control and FD hepatocytes were simultaneously measured. As shown in Fig. 4, FD hepatocytes with dysfunctional mitochondria had a significantly higher level of intracellular dihydroethidine intensity (superoxide anions) than controls, whereas intracellular $2^{\prime}, 7^{\prime}$-dichlorofluorescein diacetate intensity (mainly label of general ROS such as hydrogen peroxide) did not differ in either of the groups (Fig. 4(A, B)). Upon pro-oxidant treatment $\left(32 \mu \mathrm{mol} / 1 \mathrm{CuSO}_{4}\right)$ for $48 \mathrm{~h}$, both dihydroethidine and $2^{\prime}, 7^{\prime}$ dichlorofluorescein diacetate intensity of FD hepatocytes were significantly elevated with increase in the former (3.5-fold) being greater than the latter (1-5-fold). Preincubation of FD hepatocytes with $10-1000 \mu \mathrm{mol} / \mathrm{l}$ folic acid for $4 \mathrm{~h}$ significantly reduced intracellular dihydroethidine fluorescent intensity levels in a dose-dependent manner, with no effect on the reduction of $2^{\prime}, 7^{\prime}$-dichlorofluorescein diacetate levels.

\section{Supplemental folic acid protected pro-oxidant-challenged mitochondria from oxidative injuries}

We continued to assess whether supplemental folic acid has direct antioxidant protection against pro-oxidant-elicited oxidative injuries in mitochondria. As shown in Table 3, pro-oxidant treatment elicited less $\mathrm{mt}$ protein and lipid oxidative injury in controls compared with the FD group. Supplemental folic acid protected pro-oxidant-challenged liver mitochondria of both control and FD rats from protein and lipid peroxidation. There were strong and significant inverse correlations among supplemental folic acid levels and pro-oxidant-elicited mt oxidative injuries in both FD and control rat liver.

\section{Discussion}

The present study identified a previously unrecognized biological effect of folate in the protection of mitochondria

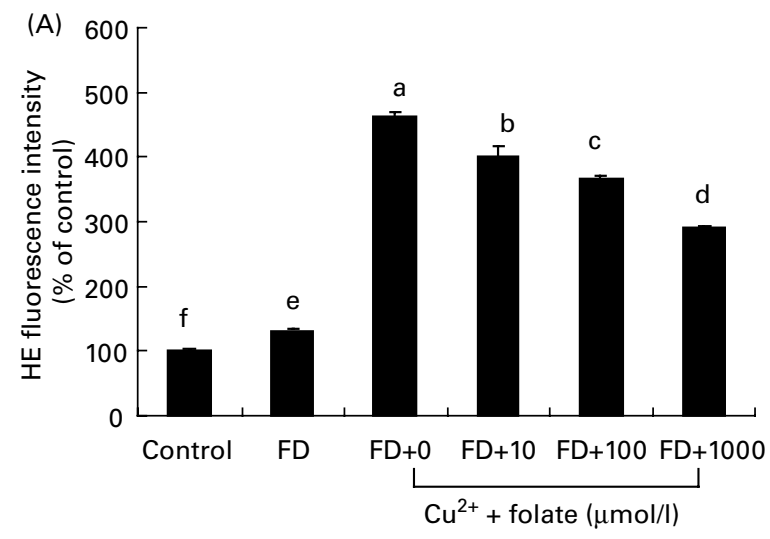

(B)

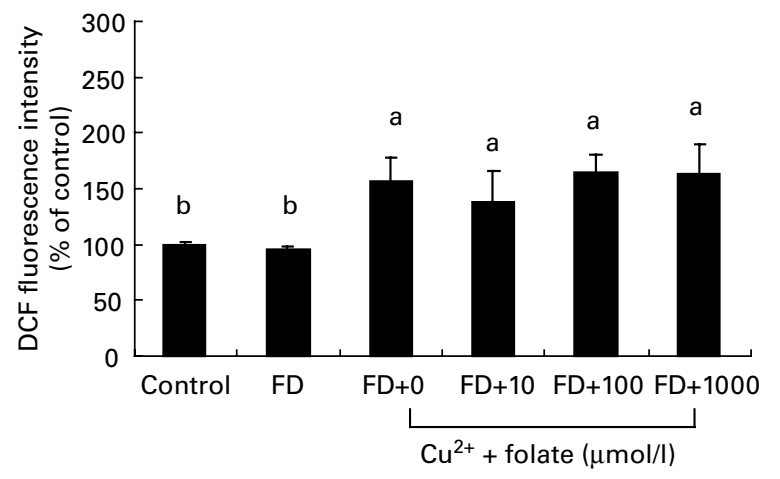

Fig. 4. Supplemental folic acid affected reactive oxygen species (ROS) production in the absence/presence of exogenous pro-oxidant challenge. Culture conditions and $\mathrm{CuSO}_{4}$ treatment are as described in Fig. 2. Intracellular superoxide and general ROS production in hepatocyte cultures were measured by dihydroethidine (HE) and $2^{\prime}, 7^{\prime}$-dichlorofluorescein diacetate (DCF) fluorescence, respectively, and analysed by flow cytometry. Values are means with their standard deviations depicted by vertical bars $(n 6) .{ }^{a-f}$ Mean values with unlike superscript letters were significantly different $(P<0.05)$. FD, folate-deficient.

against oxidative insults. The evidence of increased $\mathrm{mt}$ protein carbonyls and accumulated mtDNA ${ }^{4834}$ deletion indicate an elevated oxidative stress inside the liver mitochondria during folate deprivation (Table 1; Fig. 1). Only some measure of $\mathrm{mt}$ antioxidant defences (glutathione peroxidase activity) was altered with no obvious changes in the other markers (reduced glutathione and $\mathrm{Mn}$-superoxide dismutase), suggesting that the 4-week dietary folate deprivation promoted a moderate rather than an acute oxidative stress in liver mitochondria. Consistently, modest changes of oxidative measures with no altered reduced glutathione, vitamin $\mathrm{E}$ contents and catalase activity were found in rat liver homogenate after a 4-week folate depletion (Huang et al. 2001). The molecular basis behind this increased oxidative stress in folate-depleted mitochondria is not established. It may be partially due to a drastic drop of $\mathrm{mt}$ folate level in particular (Table 1). Reduced folate such as tetrahydrofolate and 5-methyltetrahydrofolate has been known for its antioxidant ability to scavenge free radicals in vitro (Rezk et al. 2003) and to alleviate oxidative stress in vivo (Doshi et al. 2001; Coppola et al. 2005). Alternatively, folate was reported to interact with nitric oxide synthase, improve quinonoid $\mathrm{BH}_{4}$ availability and reduce superoxide production (Stroes et al. 2000; Doshi et al. 2001). This elevated oxidative stress in folate-depleted mitochondria may also be 
Table 3. Effects of supplemental folic acid on protein carbonyl content and thiobarbituric acid-reactive substances (TBARS) levels in folate-deficient (FD) and control rat liver mitochondria under pro-oxidant stimulation $(n 6) \dagger$

(Mean values and standard deviations)

\begin{tabular}{|c|c|c|c|c|}
\hline \multirow[b]{2}{*}{ Pro-oxidant stimulation } & \multicolumn{2}{|c|}{ FD mitochondria } & \multicolumn{2}{|c|}{ Control mitochondria } \\
\hline & Mean & SD & Mean & SD \\
\hline \multicolumn{5}{|l|}{ Protein carbonyls (nmol/mg mt protein) } \\
\hline \multicolumn{5}{|l|}{ Supplemental folic acid } \\
\hline$+0 \mu \mathrm{M}$ & $4 \cdot 08^{\mathrm{ax}}$ & 0.02 & $2.55^{\text {ay }}$ & 0.03 \\
\hline$+500 \mu \mathrm{M}$ & $3.94^{\mathrm{ax}}$ & 0.02 & $1.91^{\text {by }}$ & 0.03 \\
\hline$+1 \mathrm{~mm}$ & $3.35^{\mathrm{bx}}$ & 0.37 & $1.90^{\text {by }}$ & 0.03 \\
\hline$+2.5 \mathrm{~mm}$ & $3.38^{\mathrm{bx}}$ & 0.07 & $1 \cdot 32^{\mathrm{cy}}$ & 0.04 \\
\hline$+5 \mathrm{~mm}$ & $2 \cdot 65^{\mathrm{cx}}$ & 0.03 & $0.94^{\mathrm{dy}}$ & 0.04 \\
\hline$+10 \mathrm{~mm}$ & $2 \cdot 18^{\mathrm{dx}}$ & 0.06 & $0.42^{\text {ey }}$ & 0.03 \\
\hline Folate $\times$ protein carbonyls $\S$ & $\gamma-0.865$ & $P=0.0001$ & $\gamma-0.913$ & $P=0.0001$ \\
\hline \multicolumn{5}{|l|}{ TBARS levels (nmol/mg mt protein)‡ } \\
\hline \multicolumn{5}{|l|}{ Supplemental folic acid } \\
\hline$+0 \mu \mathrm{M}$ & $5 \cdot 88^{a x}$ & 0.37 & $3 \cdot 40^{\text {ay }}$ & 0.24 \\
\hline$+500 \mu \mathrm{M}$ & $4.98^{\mathrm{abcx}}$ & 0.37 & $2 \cdot 40^{\text {aby }}$ & 0.14 \\
\hline$+1 \mathrm{~mm}$ & $5 \cdot 38^{a b x}$ & 0.37 & $3.09^{\text {aby }}$ & 0.50 \\
\hline$+2.5 \mathrm{~mm}$ & $4 \cdot 29^{\mathrm{bcx}}$ & 0.49 & $2 \cdot 60^{\text {aby }}$ & 0.37 \\
\hline$+5 \mathrm{~mm}$ & $3 \cdot 89^{\mathrm{cx}}$ & 0.29 & $2 \cdot 20^{\text {by }}$ & 0.24 \\
\hline$+10 \mathrm{~mm}$ & $3 \cdot 79^{\mathrm{cx}}$ & 0.51 & $2 \cdot 20^{\text {by }}$ & 0.24 \\
\hline Folate $\times$ lipid peroxidation $\mathrm{mt}$, mitochodrial. & $\gamma-0.824$ & $P=0.0001$ & $\gamma-0.630$ & $P=0.0051$ \\
\hline \multirow{2}{*}{\multicolumn{5}{|c|}{$\begin{array}{l}\text { a,b,c Mean values for the respective parameter within a column with unlike superscript letters were significantly different }(P<0.05 \text {; two-way ANOVA followed by } \\
\text { Dunnett's test). }\end{array}$}} \\
\hline & & & & \\
\hline \multirow{2}{*}{\multicolumn{5}{|c|}{$\begin{array}{l}x, y \text { Mean values within a row with unlike superscript letters were significantly different }(P<0.05 \text {; two-way ANOVA followed by Dunnett's test). } \\
\text { † Wistar rats were fed with the FD or control diet for } 4 \text { weeks and liver mitochondria were isolated. Aliquots of mitochondrial fraction were incubated at } 37^{\circ} \mathrm{C} \text { with }\end{array}$}} \\
\hline & & & & \\
\hline \multicolumn{5}{|l|}{$\begin{array}{l}\text { Materials and Methods. } \\
\text { Mence or } 50 \mathrm{mmol} \\
\end{array}$} \\
\hline ¥ Measured as malondialdehyde equivalents. & & & & \\
\hline
\end{tabular}

critical in the accumulation of mtDNA large deletion (Fig. 1). The occurrence of this common mtDNA deletion has been correlated with increased oxidative damage of increased 8-hydroxydeoxyguanosine (8-OHdG) levels (Lezza et al. 1999), which may cause strand breakage and recombination between homologous sequence flanking deletion site. Taken together, the present data not only confirm that folate insufficiency disrupted $\mathrm{mt}$ homeostasis but also reconcile the previous reports of folate deprivation-associated mt decay (Branda et al. 2002; Kim et al. 2002; Ho et al. 2003; Crott et al. 2005) with its antioxidant action.

The most striking finding of the present study was the specific impact of folate deficit on respiratory complex IV activity. Dietary folate restriction led to the $30 \%$ reduction of $\mathrm{CcOX}$ activity in rat liver mitochondria, whereas other respiratory chain activities of complex I, II and III were not affected (Table 2). The reduced $\mathrm{CcOX}$ activity in FD hepatocytes or in pro-oxidant-treated hepatocytes can be restored by supplemental folic acid (Fig. 2). To our knowledge, this is the first in vivo evidence indicating that folate status could modulate $\mathrm{CcOX}$ activity, confirming the finding in the in vitro study by Brookes \& Baggott (2002) to identify complex IV as the site of electron donation by 10 -formyl-tetrahydrofolate in isolated rat liver mitochondria. The molecular mechanisms by which folate modulates $\mathrm{CcOX}$ activity, however, remain largely unknown. Several possible regulations are plausible. (1) Since FD-induced mtDNA large deletions result in a loss of the CcOXIII gene (Fig. 1(B)), one may speculate that this decreased copy number of the $\mathrm{CcOXIII}$ gene in FD tissues may cause an impaired $\mathrm{CcOX}$ protein leading to $\mathrm{CcOX}$ dysfunction. This postulation is supported by the fact that large-scale deletions of mtDNA have been associated with $\mathrm{CcOX}$ dysfunction in human $\mathrm{mt}$ disorders and the ageing process (Schon et al. 1997). (2) The decline of CcOX activity can be attributed to a specific alteration in the mt cardiolipin content, probably due to a peroxidative attack of the phospholipids by $\mathrm{mt}$ ROS (Paradies et al. 2000). The antioxidant properties of folate in mitochondria, as previously demonstrated, highly support this possibility. Indeed, the reduced $\mathrm{CcOX}$ activity in pro-oxidant-treated hepatocytes correlated with increased lipid peroxidation in liver mitochondria, both of which were reversible by supplemental folic acid (Fig. 2; Table 3). (3) It cannot be excluded that mutations in genes of $\mathrm{CcOX}$ subunits may contribute to $\mathrm{CcOX}$ dysfunction of FD rat liver. Gene mutations in CcOX I-III subunits (Hoffbuhr et al. 2000; D'Aurelio et al. 2001) as well as CcOX assembly factors (Sue et al. 2000) have been associated with $\mathrm{CcOX}$ dysfunction. Folate deficiency has been known to increase chromosomal instability and promote genetic mutations (Duthie et al. 2002). Further studies are warranted to elucidate the genetic and epigenetic mechanisms of folate in the regulation of $\mathrm{CcOX}$ function.

The impaired $\mathrm{CcOX}$ protein function by chemicals, pro-oxidants or by hypoxia has been shown to cause an accumulation and leakage of electrons from the early complexes, disturbed mt membrane potential and increased superoxide production (Ksenzenko et al. 1983; Hagen et al. 1997; Duranteau et al. 1998; Paradies et al. 2000; Palacios-Callender et al. 2004). Consistently, FD hepatocytes with $\mathrm{CcOX}$ deficit displayed mt membrane depolarization and a concomitant increase of 
intracellular superoxide levels (Figs. 2-4). The reduced $\mathrm{CcOX}$ activity in pro-oxidant-treated FD hepatocytes was reversible by supplemental folate, which coincided with a normalized mt membrane potential as well as a corresponding decrease of intracellular superoxide levels. Thus, the evidence suggests that superoxide scavenging capability of folate observed in both the present and other studies (Doshi et al. 2001; Huang et al. 2002, 2004) may be in part mediated through modulating $\mathrm{mt} \mathrm{CcOX}$ and membrane function.

It should be noted that the supplemental folate used in the present study to protect liver mt against endogenous or prooxidant-induced oxidative injuries was folic acid. Folic acid is not a natural substance and therefore may not be taken up by cells and cross the mt membrane. Presumably, the added folic acid in animal diets or in folic acid-supplemented medium must be metabolized to natural forms of reduced folate by dihydrofolate reductase in order to cross the $\mathrm{mt}$ membrane. Indeed, our in vivo and ex vivo data suggest that folic acid is biologically active to protect mitochondria from oxidative injuries. On the other hand, the effective dose of folic acid to counteract $\mathrm{mt}$ oxidative injuries in the present study was found at micromolar levels, which are much greater than those encountered in the human physiological system (nanomolar levels). One will raise the question whether effects of folic acid found in the present study have physiological relevance. Future studies are warranted to investigate the influence of physiologically relevant reduced folate metabolites and concentrations on $\mathrm{mt}$ function.

In conclusion, the present findings identify an antioxidant action of folic acid to protect against $\mathrm{mt}$ oxidative injuries, CcOX dysfunction and membrane depolarization. Supplemental folic acid attenuates the oxidative defects in mitochondria of pro-oxidant-treated hepatocytes. Implication of increased folic acid levels as a possible determinant of mt function may unveil a new potential target to reduce intracellular superoxide overproduction. The question as to whether folic acid supplementation may present an effective dietary strategy to help improve oxidative stress-related mitochondria disorders or ageing-associated conditions in man, however, requires further study.

\section{Acknowledgements}

The authors acknowledge Prof. C. K. Lii (Department of Nutritional Sciences, Chung Shan Medical University) for guidance in the techniques of primary hepatocyte isolation. The authors are deeply grateful to Prof. Y.-H. Wei in the Department of Biochemistry at the National Yang-Ming University for the kind support and invaluable advice on mitochondrial DNA mutations. We thank Dr Y.-A. Lee in the Department of Life Science and Dr J. F. Lu in the Department of Medicine for helpful discussion of primer design and mitochondrial extraction. Dr B. Stephen Inbaraj's efforts in the English editing of this manuscript is appreciated. This study was supported by grants from the National Science Council, Taiwan (NSC 91-2320-B030-002, NSC94, 95-2320-B-030-002 to R. F. S. Huang).

\section{References}

Bradford MM (1976) A rapid and sensitive method for the quantitation of microgram quantities of protein utilizing the principle of protein-dye binding. Anal Biochem 72, 248-254.
Branda RF, Brooks EM, Chen Z, Naud SJ \& Nicklas JA (2002) Dietary modulation of mitochondrial DNA deletions and copy number after chemotherapy in rats. Mutat Res 501, 29-36.

Brookes PS \& Baggott JE (2002) Oxidation of 10-formyltetrahydrofolate to 10-formyldihydrofolate by complex IV of rat mitochondria. Biochemistry 41, 5633-5636.

Cadenas E \& Davies KJA (2000) Mitochondrial free radical generation, oxidative stress, and aging. Free Radic Biol Med 29, 222-230.

Chen YH, Huang RFS, Wei JS \& Liu TZ (2001) Folate deficiencymediated down regulation of intracellular glutathione and antioxidant enzymes increases susceptibility of human hepatoma HepG2 cells to various oxidant stress-induced cytotoxicity. J Biomed Lab Sci 13, 52-57.

Chern CL, Huang RFS, Chen YH, Cheng JT \& Liu TZ (2001) Folate deficiency-induced oxidative stress and apoptosis are mediated via homocysteine-dependent overproduction of hydrogen peroxide and enhances activation of NF- $\mathrm{KB}$ in human HepG2 cells. Biomed Pharmacother 55, 434-442.

Coppola A, D'Angelo A, Fermo I, et al. (2005) Reduced in vivo oxidative stress following 5-methyltetrahydrofolate supplementation in patients with early-onset thrombosis and 677TT methylenetetrahydrofolate. Br J Haematol 131, 100-108.

Cortopassi GA, Shibata DD, Soong NW \& Amheim N (1992) A pattern of accumulation of a somatic deletion of mitochondrial DNA in aging human tissues. Proc Natl Acad Sci U S A 89, 7370-7374.

Cortopassi G \& Wang E (1995) Modelling the effects of age-related mtDNA mutation accumulation; complex I deficiency, superoxide and cell death. Biochim Biophys Acta 1271, 171-176.

Crott JW, Choi SW, Branda RF \& Mason JB (2005) Accumulation of mitochondrial DNA deletions is age, tissue and folate-dependent in rats. Mutat Res 570, 63-70.

D'Aurelio M, Pallotti F, Barrientos A, et al. (2001) In vivo regulation of oxidative phosphorylation in cells harboring a stop-codon mutation in mitochondrial DNA-encoded cytochrome c oxidase subunit I. J Biol Chem 276, 46925-46932.

Doshi SN, McDowell IFW, Moat SJ, et al. (2001) Folate improves endothelial function in coronary artery disease. An effect mediated by reduction of intracellular superoxide? Arterioscler Thromb Vasc Biol 21, 1196-1202.

Duranteau J, Chandel NS, Kulioz A, Shao Z \& Schumacher PT (1998) Intracellular signaling by reactive oxygen species during hypoxia in cardiomyocytes. J Biol Chem 273, 11619-11624.

Duthie SJ, Narayanan S, Brand GM, Pirie L \& Grant G (2002) Impact of folate deficiency on DNA stability. $J$ Nutr 132, 2444S-2449S.

Edris W, Burgett B, Stine OC \& Filburn CR (1994) Detection and quantitation by competitive PCR of an age-associated increase in a $4.8 \mathrm{~kb}$ deletion in rat mitochondrial DNA. Mutat Res 316, 69-78.

Evans WH (1992) Isolation and characterization of membranes and cell organelles. In Preparative Centrifugation: A Practical Approach, pp. 233-270 [D Rickwood, editor]. New York: Oxford University Press.

Fraga CG, Leibovitz BE \& Tappel AL (1988) Lipid peroxidation measured as thiobarbituric-reactive substances in tissue slices: characterization and comparison with homogenates and microsomes. Free Radic Biol Med 4, 155-161.

Hagen TM, Yowe DL, Bartholomew JC, Wehr CM, Do KL, Park JY \& Ames BN (1997) Mitochondrial decay in hepatocytes from old rats: membrane potential declines, heterogeneity and oxidants increase. Proc Natl Acad Sci U S A 94, 3064-3069.

Hissin PJ \& Hilf R (1976) A fluorometric method for determination of oxidized and reduced glutathione in tissues. Anal Biochem 74, 214-226.

Ho PI, Ashline D, Dhitavat S, et al. (2003) Folate deprivation induces neurodegeneration; roles of oxidative stress and increased homocysteine. Neurobiol Dis 14, 32-42.

Hoffbuhr KC, Davidson E, Filiano BA, et al. (2000) A pathogenic 15base pair deletion in mitochondrial DNA-encoded cytochrome $\mathrm{c}$ 
oxidase subunit III results in the absence of functional cytochrome c oxidase. J Biol Chem 275, 13994-14003.

Horne DW \& Patterson D (1988) Lactobacillus casei microbiological assay of folic acid derivatives in 96-well microtiter plates. Clin Chem 34, 2357-2359.

Huang RFS, Hsu YC, Lin HL \& Yang FL (2001) Folate depletion and elevated plasma homocysteine promote oxidative stress in rat livers. J Nutr 131, 33-38.

Huang RFS, Huang SM, Lin BS, Hung CY \& Lu HT (2002) N-Acetylcysteine, vitamin $\mathrm{C}$ and vitamin $\mathrm{E}$ diminish homocysteine thiolactone-induced apoptosis in human promyeloid HL-60 cells. J Nutr 132, 2151-2155.

Huang RFS, Yaong HC, Chen SC \& Lu YF (2004) In vitro folate supplementation alleviates oxidative stress, mitochondria-associated death signaling and apoptosis induced by 7-ketocholesterol. $\mathrm{Br} \mathrm{J}$ Nutr 92, 887-894.

Johnson D \& Lardy H (1967) Isolation of liver or kidney mitochondria. Methods Enzymol 10, 94-96.

Joshi R, Adhikari S, Patro BS, Chattopadhyay S \& Mukherjee T (2001) Free radical scavenging behavior of folic acid: evidence for possible antioxidant activity. Free Radic Biol Med 30, 1390-1399.

Kim JM, Lee H \& Chang N (2002) Hyperhomocysteinemia due to short-term folate deprivation is related to electron microscopic changes in the rat brain. $J$ Nutr 132, 3418-3421.

Ksenzenko M, Konstantinov AA, Khomutov GB, Tikhonov AN \& Ruuge EK (1983) Effect of electron transfer inhibitors on superoxide generation in the cytochrome bc1 site of the mitochondrial respiratory chain. FEBS Lett 155, 19-24.

Lee HC, Pang CY, Hsu HS \& Wei YH (1994) Differential accumulations of 4977 bp deletion in mitochondrial DNA of various tissues in human ageing. Biochim Biophys Acta 1226, 37-43.

Lii CK \& Hendrich S (1993) Selenium deficiency suppresses the $S$-glutathiolation of carbonic anhydrase III in rat hepatocytes under oxidative stress. $J$ Nutr 123, 1480-1486.

Lezza AMS, Mecocci P, Cormio A, Beal FM, Cherubini A, Cantatore P, Senin U \& Gadaleta MN (1999) Mitochondrial DNA 4977 bp deletion and OH8dG levels correlate in the brain of aged subjects but not Alzheimer's disease patients. FASEB $J \mathbf{1 3}$, $1083-1088$.

Lu CY, Lee HC, Fahn HJ \& Wei YH (1999) Oxidative damage elicited by imbalance of free radical scavenging enzymes is associated with large-scale mtDNA deletions in aging human skin. Mutat Res 423, 11-21.

Marklund S \& Marklund G (1974) Involvement of the superoxide anion radical in the autoxidation of paragallol and a convenient assay for superoxide dismutase. Eur J Biochem 47, 469-474.

Mayer O Jr, Simon J, Rosolova H, et al. (2002) The effects of folate supplementation on some coagulation parameters and oxidative status surrogates. Eur J Clin Pharmacol 58, 1-5.
Nakano E, Higgins JA \& Powers HJ (2001) Folate protects against oxidative modifications of human LDL. Br J Nutr 86, 637-639.

Palacios-Callender M, Quintero M, Hollis VS, Springett RJ \& Moncada S (2004) Endogenous NO regulates superoxide production at low oxygen concentrations by modifying the redox state of cytochrome c oxidase. Proc Natl Acad Sci U S A 101, 7630-7635.

Paradies G, Petrosillo G, Pistolese M \& Ruggiero FM (2000) The effect of reactive oxygen species generated from the mitochondrial electron transport chain on the cytochrome c oxidase activity and on the cardiolipin content in bovine heart submitochondrial particles. FEBS Lett 466, 323-326.

Ravagnan L, Roumier T \& Kroemer G (2002) Mitochondria, the killer organelles and their weapons. J Cell Physiol 192, $131-137$

Rezk BM, Haenen GRMM, van der Vijgh WJF \& Bast A (2003) Tetrahydrofolate and 5-methyltetrahydrofolate are folates with high antioxidant activity. Identification of the antioxidant pharmacophore. FEBS Lett 555, 601-605.

Reznick AZ \& Packer L (1994) Oxidative damage to proteins: spectrophotometric method for carbonyl assay. Methods Enzymol 233, 357-363.

Schon EA, Bonilla E \& Dimauro S (1997) Mitochondrial DNA mutations and pathogenesis. J Bioenerg Biomembr 29, 131-149.

Seligman AM, Karnovsky MJ, Wasserkrug HL \& Hanker JS (1968) Nondroplet ultrastructural demonstration of cytochrome oxidase activity with a polymerizing osmiophilic reagent, diaminobenzidine (DAB). J Cell Biol 38, 1-14.

Shane B (1995) Folate chemistry and metabolism. In Folate in Health and Disease, pp. 1-22 [LB Bayley, editor]. New York: Marcel Dekker.

Stroes ES, van Faassen EE, Yo M, et al. (2000) Folic acid reverts dysfunction of endothelial nitric oxide synthase. Circ Res 86, $1129-1134$.

Sue CM, Karadimas C, Checcarelli N, et al. (2000) Differential features of patients with mutations in two COX assembly genes, SURF-1 and SCO2. Ann Neurol 47, 589-595.

Tappel AL (1977) Glutathione peroxidase and hydroperoxides. Methods Enzymol 52, 506-513.

Trounce IA, Kim YL, Jun AS \& Wallace DC (1996) Assessment of mitochondrial oxidative phosphorylation in patient muscle biopsies, lymphoblasts, and transmitochondrial cell lines. Methods Enzymol 264, 484-509.

Turrens JF, Alexandre A \& Lehninger AL (1985) Ubisemiquinone is the electron donor for superoxide formation by complex III of heart mitochondria. Arch Biochem Biophys 237, 408-414.

Walzem RL \& Clifford AJ (1988) Folate deficiency in rats fed diets containing free amino acid or intact proteins. J Nutr $\mathbf{1 1 8}$, 1089-1096. 